УДК 373.5.041:316.61]:54, де 373.5.041

DOI https://doi.org/10.32782/apv/2021.3.32

\title{
Ірина ССІКОВА
}

аспірантка кафедри освітології та інноващійної педагогіки, Харківський національний педагогічний університет імені Г.С. Сковороди, вул. Валентинівська, 2, м. Харків, Україна, 61168

ORCID: 0000-0003-0794-2781

Бібліографічний опис статті: Єсікова, І. (2021). Тенденції розвитку інклюзивної освіти під час вивчення хімії в умовах дистанційного навчання в закладах загальної середньої освіти. Acta Paedagogica Volynienses, 3, 219-224, doi: https://doi.org/10.32782/apv/2021.3.32

\section{ТЕНДЕНЦІЇ РОЗВИТКУ ІНКЛЮЗИВНОЇ ОСВІТИ ПІД ЧАС ВИВЧЕННЯ ХІМІЇ В УМОВАХ ДИСТАНЦІЙНОГО НАВЧАННЯ В ЗАКЛАДАХ ЗАГАЛЬНОЇ СЕРЕДНЬОЇ ОСВІТИ}

У статті висвітлено тенденції розвитку інклюзивної освіти під час вивчення хімії в умовах дистанційного навчання. Розглянуто поняття «віртуальна лабораторія», охарактеризовано види віртуальних засобів, щио надають можливість всім учасникам навчального процесу, незалежно від фізичних можливостей робити хімічні експерименти та актуальність їх застосування в інклюзивному середовищі закладів загальної середньої освіти.

Мета статті полягає в аналізі віртуальних хімічних лабораторій та їх можливостей, перевіриі їх ефективності під час навчання дітей з особливими освітніми потребами. Проаналізовано літературні джерела із використання віртуального хімічного експерименту на уроках хімії під час навчання дітей з особливими потребами. На основі досліджень визначено переваги та недоліки використання віртуальних лабораторій, їх позитивний вплив на процес навчання дітей з особливими потребами.

Здійснено огляд сучасних віртуальних хімічних засобів навчання котрі доцільно використовувати в інклюзивному середовищі під час вивчення хімії. Наведено приклади віртуальних хімічних лабораторій, котрі визнані в Україні та за ї̈ межами, а саме: ChemCollective, phet.colorado.edu, Chemist Free-Virtual Chem Lab, VirtuLab. Описано їх функиіональні можливості та методику застосування як спеціально розроблених програмних засобів, для застосування в освітніх иүілях в інклюзивному середовищі закладів загальної середньої освіти.

Встановлено, щуо віртуальні хімічні лабораторії дають змогу виконувати хімічний експеримент всім, незалежно від фізичних особливостей учнів. Надають можливість учням котрі були відсутні на занятті виконувати досліди, забезпечують індивідуальний темп виконання досліду та мотивують до засвоєння нового матеріалу шляхом роботи в віртуальному середовищі.

Отже, проведення хімічних експериментів за допомогою віртуальних лабораторій дозволяє ефективно вирішити низку навчальних задач таких як безпечність для здоров'я учнів, фінансова недоступність та можливість навчатися та виконувати досліди в період пандемії та дистанційного навчання. Вказано перспективні напрями продовження дослідження.

Ключові слова: інформаційно-комунікаційні технології, дистанційна освіта, віртуальні хімічні лабораторії, інклюзивна освіта.

\section{Irina YESIKOVA}

Postgraduate Student at the Department of Education and Innovative Pedagogy, H.S. Skovoroda Kharkiv National Pedagogical University, Valentynivska str., 2, Kharkiv, Ukraine, 61168

ORCID: 0000-0003-0794-2781

To cite this article: Yesikova, I. (2021). Tendentsiyi rozvytku inklyuzyvnoyi osvity pry vyvchennya khimiyi $\mathrm{v}$ umovakh dystantsiynoho navchannya $\mathrm{v}$ zakladakh zahal'noyi seredn'oyi osvity [Trends in the development of inclusive education in the study of chemistry in distance learning in general secondary education]. Acta Paedagogica Volynienses, 3, 219-224, doi: https://doi.org/10.32782/apv/2021.3.32

\section{TRENDS IN THE DEVELOPMENT OF INCLUSIVE EDUCATION IN THE STUDY OF CHEMISTRY IN THE CONDITIONS OF DISTANCE LEARNING IN GENERAL SECONDARY EDUCATION INSTITUTIONS}

This article highlights the trends in inclusive education in the study of chemistry in distance learning. The concept of "virtual laboratory" is considered, the types of virtual tools that allow all participants in the learning process, regardless 
of physical capabilities to do chemical experiments and the relevance of their use in an inclusive environment of general secondary education.

The purpose of the article is to analyze virtual chemical laboratories and their capabilities, to test their effectiveness in teaching children with special educational needs. Literature sources on the use of virtual chemical experiment in chemistry lessons in teaching children with special needs are analyzed. Based on research, the advantages and disadvantages of using virtual laboratories, their positive impact on the learning process of children with special needs have been identified.

A review of modern virtual chemical teaching aids that should be used in an inclusive environment in the study of chemistry. Examples of virtual chemical laboratories that are recognized in Ukraine and abroad are given, namely: ChemCollective, phet.colorado.edu, Chemist Free-Virtual Chem Lab, VirtuLab. Their functionality and methods of application as specially developed software for use for educational purposes in an inclusive environment of general secondary education are described.

It has been established that virtual chemical laboratories allow anyone to perform a chemical experiment, regardless of the physical characteristics of students. They provide an opportunity for students who were absent from the class to perform experiments, provide an individual pace of the experiment and motivate them to learn new material by working in a virtual environment.

Thus, conducting chemical experiments with the help of virtual laboratories allows to effectively solve a number of educational tasks such as safety for students' health, financial inaccessibility and the ability to learn and perform experiments during the pandemic and distance learning. Promising areas for further research are indicated.

Key words: information and communication technologies, distance education, virtual chemical laboratories, inclusive education.

\section{Постановка проблеми в загальному} вигляді. В умовах пандемії, коли весь світ перебуває в умовах необхідності працювати по-іншому, неможливо уявити сучасний навчальний процес без застосування інноваційних технологій. Поняття навчання в режимі online (тобто через Internet) стало традиційним. Загроза поширення коронавірусної інфекції (COVID-19) та стрімкі темпи розвитку інноваційних підходів до навчання, такі як дистанційне навчання, змішане (гібридне або комбіноване) зумовили необхідність реформування навчального процесу.

Згідно 3 Положенням про дистанційне навчання, яке затверджено наказом Міністерства освіти і науки України від 25.04.2013 р. № 466, під дистанційним навчанням розуміється індивідуалізований процес набуття знань, умінь, навичок і способів пізнавальної діяльності людини, який відбувається в основному за опосередкованої взаємодії віддалених один від одного учасників навчального процесу у спеціалізованому середовищі, яке функціонує на базі сучасних психологопедагогічних та інформаційно-комунікаційних технологій (Положення, 2004; Положення, 2013).

Основними завданнями Національної стратегії розвитку освіти в Україні на період до 2021 року в загальній середній освіті є оновлення змісту, форм і методів організації навчально-виховного процесу; створення умов для посилення професійної орієнтації учнівської молоді, забезпечення індивідуальної освітньої траєкторії розвитку учнів від- повідно до їхніх особистісних потреб, інтересів і здібностей; підвищення ефективності навчально-виховного процесу на основі впровадження досягнень психологопедагогічної науки, педагогічних інновацій, інформаційнокомунікаційних технологій (ІКТ) (Про національну стратегію, 2013).

Аналіз останніх досліджень і публікацій. Питання інтеграції та соціалізації осіб з особливими потребами розкриті у працях вітчизняних та закордонних дослідників О. В. Безпалька, Е. В. Жулиної, І. Б. Іванової, А. Й. Капської, В. А. Кудрявцева, Г. М. Лактіонової та ін.

Питання застосування технологій дистанційного навчання присвятили свої наукові праці багато вітчизняних та зарубіжних вчених, серед яких особливий внесок зробили: О. М. Андреєва, В.О. Колос, С.М. Березенська, В.Ю. Ващенко, К.Л. Бугайчук, О.В. Рибалко, B.М. Кухаренко, В.І. Алещенко та ін.

Підходами до визначення «віртуальна лабораторія» займалися такі вчені, як A. Alexiou, Ch. Bouras, I.Б. Галелюка, Т.М.Гранкіна, Т.А. Клименко, Т.I. Нарожна, М.Н. Морозов, Т. Підгірна.

В умовах пандемії вірусу COVID-19 питання застосування інформаційно-комунікаційних технологій навчання та реалізації технологій дистанційного навчання на уроках хімії $\epsilon$ особливо актуальним.

Метою статті $\epsilon$ я $€$ аналіз віртуальних хімічних лабораторій та їх можливостей, перевірка ïх ефективності під час навчання дітей 3 особливими освітніми потребами. 
Реалізація передбачала виконання завдань: 1) проаналізувати віртуальні лабораторії та їх можливості; 2) перевірити їх ефективність та визначити можливі недоліки під час навчання дітей з особливими освітніми потребами.

Відповідно до мети дослідження були використані такі методи і методики дослідження: теоретико-методичний аналіз і синтез науковометодичної літератури та нормативних документів); вивчення й аналітичне узагальнення впровадження віртуальних лабораторій під час навчання дітей з особливими потребами.

Виклад основного матеріалу. Одним із різновидів ІКТ, що набули популярності під час вивчення хімії, $є$ віртуальні лабораторії, котрі залучають всіх учнів незалежно від фізичних особливостей до проведення експерименту. Виконання лабораторних робіт в класі з дітьми з особливими освітніми потребами потребують значної уваги.

Як зазначають дослідники, віртуальна лабораторія є навчальним середовищем, яке дає змогу віртуально виконувати хімічні експерименти і дає змогу оволодівати новими знаннями та вміннями. (Semenihina, Shamonya, 2011) Вона повністю замінює шкільну лабораторію з її установками та матеріалами, весь процес організації досліду виконую комп'ютер, а дослідник лише має правильно його налаштувати та виконувати експеримент (Юрченко, Хворостіна, 2016).

Згідно 3 визначенням О.В. Трухіна віртуальна лабораторія - це програмно-апаратний комплекс, який дає змогу проводити досліди без наявності реальної установки (Трухин, 2002).

Віртуальні хімічні лабораторії мають ряд переваг, які полягають:

1) у відсутності необхідності придбання коштовного матеріального забезпечення й реактивів: в більшості шкільних хімічних лабораторій, через недостатнє фінансування, залишилось у наявності лише старе обладнання, що може створювати потенційну небезпеку для учнів під час проведення дослідів,

2) у можливості моделювання процесів, для перебігу і спостереження котрих необхідно спеціальні умови (надвисокі або наднизькі температури, тиски, використання небезпечних для здоров'я або рідкісних речовин, додаткового обладнання тощо);

3) у відсутності ризику для життя і здоров'я учнів, пов'язаних із проведенням реальних експериментів, особливо якщо у них застосовуються токсичні або їдкі речовини, легкозаймисті матеріали, електричні прилади тощо;

4) у можливості використання віртуальної хімічної лабораторії для дистанційного та інклюзивного навчання, що полягає у організації виконання лабораторних робіт навіть у разі відсутності можливості доступу до шкільних лабораторій, наприклад під час роботи з дітьми, в яких обмежені фізичні можливості, які пропускають відповідні заняття через хворобу;

5) у комфортності сприйняття інформації учнями, для яких 3 дитинства звичними джерелами інформації є комп'ютери, смартфони та інші гаджети;

6) у можливості застосування віртуальної хімічної лабораторії в дистанційному навчанні, коли немає можливості відвідувати лабораторії в закладі навчання (Трухин, 2002).

Прикладами віртуальних хімічних лабораторій, котрі визнані в Україні та за ії межами $\epsilon$ ChemCollective, phet.colorado.edu, Chemist Free- Virtual Chem Lab, VirtuLab.

ChemCollective - безкоштовний для встановлення, використання та поширення програмний засіб. Користуватись ним можна як онлайн запустивши віртуальні лабораторії з сайту, так i офлайн, завантаживши файли інсталяції для подальшого встановлення програми на ПК. Для запуску програми - симулятора хімічної лабораторії необхідний файл VLab.exe (VLabUK. ехе - для україномовної версії).

У вікні програми (рис. 1.), Панель «Меню» знаходиться зверху, в ній розташовано 5 вкладок. У вкладці «файл» можна завантажити завдання, створити новий робочий стіл, перейменувати його або видалити.

У вкладці «Редагування» можна скасовувати дії, повторювати, копіювати, видаляти, перейменовувати та термічні можливості.

У вкладці «Спорядження» можна обрати посуд а саме: хімічні стакани, піпетки, мірні колби різних об'ємів, конічні колби, мірні циліндри, а також бюретку на 50 мл. та пінополістиреновий стакан.

Можна обрати обладнання: човник для зважування та терези, пальник Бунзена.

Наступна вкладка «Вигляд» дає змогу змінити тему робочого столу.

Вкладка «Допомога» містить зміст програми й інформацію про віртуальну лабораторію. 
У вікні програми (рис. 1), ліва панель назва якої «Препараторська», в ній зберігаються хімічні реактиви.

По центру розташована область під назвою «Робочий стіл», місце для проведення дослідів. На робочий стіл можна винести усі необхідні, для експерименту компоненти: реактиви, посуд, обладнання, та працювати з ними.

На правій стороні панелі знаходиться інформація про речовину або суміш: її назва, кількість речовин, агрегатний стан, об'єм, концентрація (моль/л або г/л), показання спектрометру, термометру, $\mathrm{pH}$-метру.

Натепер програмне забезпечення ChemCollective охоплює стехіометрію, термохімію, кінетику, рівновагу, кислотно-основну хімію, розчинність, окиснено-відновні процеси, електрохімію, аналітичну та фізичну хімію.

Програма в умовах дистанційного навчання дає змогу учням виконувати хімічні досліди, спостерігати хімічні процеси, обирати із сотень стандартних реагентів та користуватися ними, як в справжній лабораторії (ChemCollective).

Phet.colorado.edu - безкоштовний ресурс 3 моделювання експериментів. Має зручний інтерфейс українською мовою, нескладний в управлінні, дозволяє самостійно складати й проводити експерименти за допомогою віртуальних приладів. За допомогою цього ресурсу можна віртуально провести фактично всі демонстраційні та лабораторні роботи 3 загальної та квантової хімії. Користування сторінкою буде корисним також і під час очного навчання - на сайті можна попередньо моделювати параметри експерименту, а, впевнившись, що жоден прилад не постраждає від некоректного використання, тоді вже ставити реальний дослід.

Користуватись ним можна онлайн запустивши програму - симулятора хімічної лабораторії 3 сайту.

У вікні програми (рис. 2), панель «Меню» знаходиться зверху, в ній знаходиться 7 вкладок.

У вкладці «симулятори» можна обрати предмет.

У вкладці «навчання» можна ознайомитися 3 порадами по використанню phet, знайти за класифікатором,переглянути та поділитися своїми розробками та перейти до віртуальної майстерні.

Вкладка «дослідницька робота» містить інформацію як створюються симулятори, відповіді на найчастіші запитання та публікації і презентації.

Наступна вкладка «доступність» дає змогу ознайомитися 3 доступними симуляціями та їх спеціальними можливостями.

По центру розташовані усі симулятори 3 назвами експериментів, потрібно обрати потрібний, натиснути на нього та починати виконувати хімічний експеримент.

Зліва знаходиться вкладка «предмет» в якій можна обрати предмет та його розділи, клас та доступність (PhET).

Chemist Free- Virtual Chem Lab - красиво візуалізований додаток, має як практичну можливість позмішувати реактиви, так і лаконічне теоретичне пояснення. На жаль, в безкоштов-

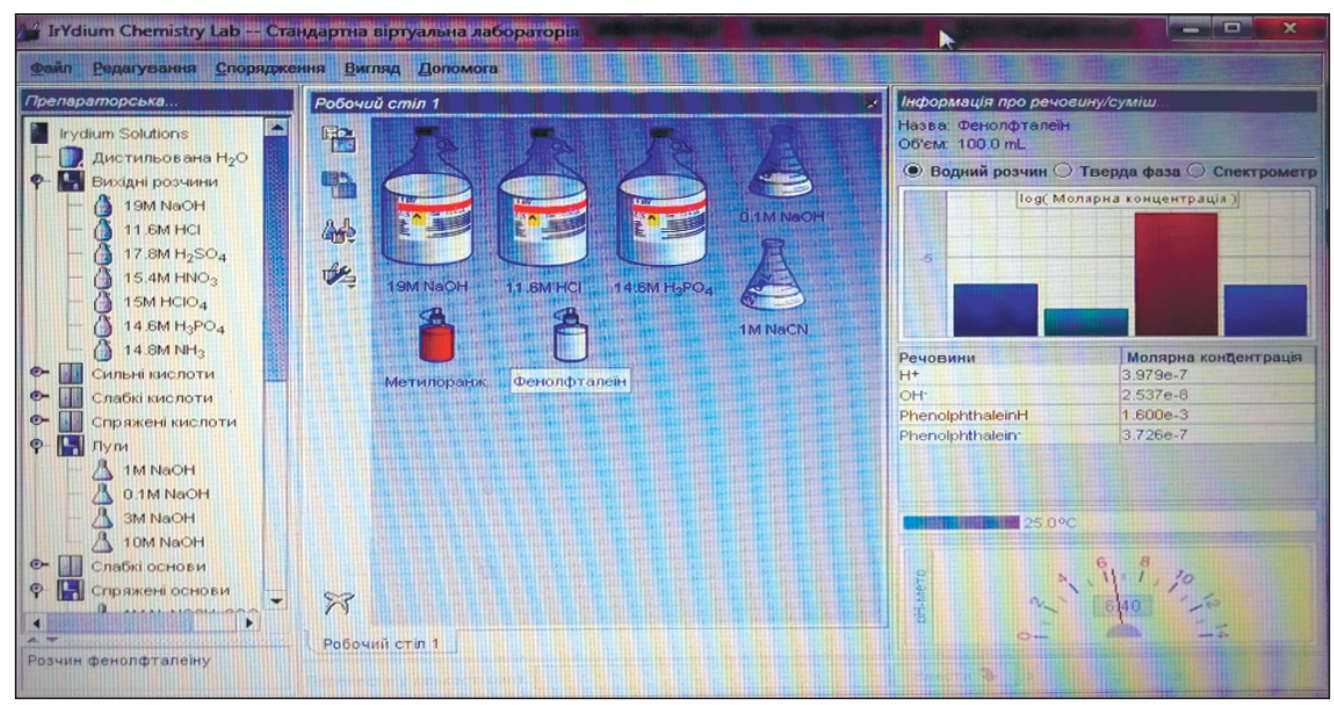

Рис. 1. ВХЛ VLab під час роботи 


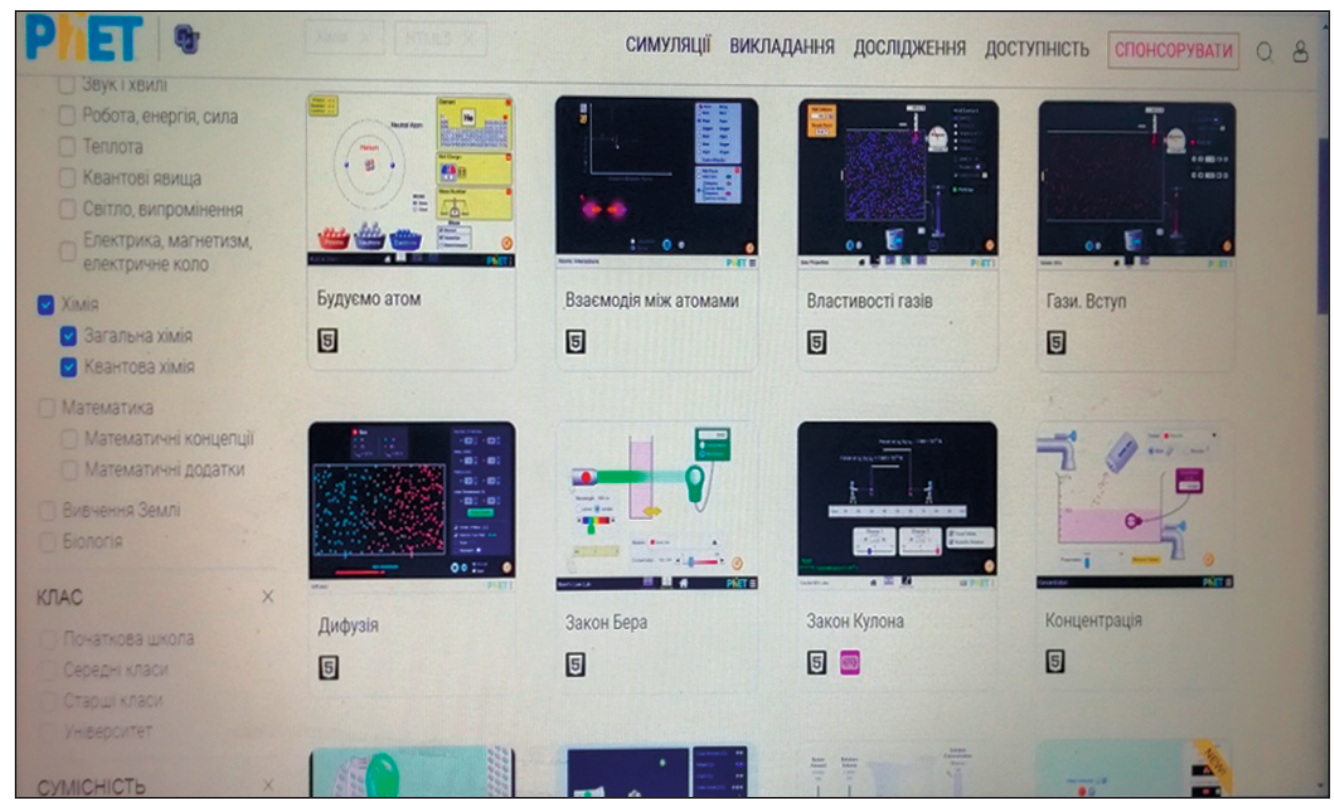

Рис. 2. ВХЛ РһЕТ під час роботи

ній версії доволі мало реактивів і можливостей, до того ж в ній можна зробити експерименти лише з неорганічної хімії (Chemist Free- Virtual Chem Lab).

VirtuLab - віртуальна лабораторія, яка складається з інтерактивних практичних робіт та дослідів для закріплення ключових моментів у вивченні хімії. Вона досить зручна у використанні. Для того, щоб виконати лабораторну роботу, потрібно перед початком роботи опрацювати теорію, так як в додатку вона відсутня. Саму роботу можна виконати лише за чітким сценарієм, тож імпровізувати і творчо хімічити в ній не вийде. Інформація подана стисло та адекватно. Віртуальна лабораторія містить досліди для ознайомлення зі зразками простих і складних речовин, мінералів і руд, вивчення фізичних і хімічних властивостей деяких з них (VirtuLab).

Використання освітнього ресурсу «Віртуальна лабораторія з хімії» дає можливість виконувати експеримент за відсутності складного обладнання та малодоступних реактивів, дозволяє учням $з$ особливими освітніми потребами працювати індивідуально та власноруч виконувати хімічний експеримент. На нашу думку, в освітньому процесі найкраще поєднувати віртуальні хімічні лабораторії та традиційне виконання хімічного експерименту, використовуючи переваги кожного, для забезпечення якісного навчання та зацікавлення учнів хімією.

Виконання хімічного досліду в віртуальній хімічній лабораторії не замінить традицій- ного виконання лабораторної роботи, це є гарним доповненням для виконання дослідів для учнів котрі були відсутні на занятті, виконувати досліди, які не включені до навчальної програми, та надає можливість навчатися та виконувати досліди в період пандемії та дистанційного навчання.

Висновки i перспективи подальших досліджень. У статті перелічені та охарактеризовані віртуальні лабораторії та їх можливості, які доцільно використовувати під час навчання дітей $з$ особливими освітніми потребами на уроках хімії.

Віртуальні хімічні лабораторії являють собою програмно-апаратні комплекси, які надають змогу здійснювати хімічні експерименти без використання користувачем реальних хімічних речовин та обладнання. Вони надають віддалений доступ до обладнання реальної лабораторії тим самим роблять заняття більш цікавим, наочним, залучаючи учнів до активно пізнавальної і дослідницької діяльності.

Проведення хімічних експериментів за допомогою віртуальних лабораторій дозволяє ефективно вирішити низку навчальних задач таких як безпечність для здоров'я учнів, фінансова недоступність.

Наше дослідження не вичерпує всіх аспектів проблеми. Подальшого вивчення потребує впровадження віртуальних хімічних лабораторій в практику сучасної української школи, створення та адаптування програмно- 
апаратних комплексів 3 хімії для навчання дітей 3 особливими освітніми потребами та готовність вчителів до їх використання, та вдосконалення власних компетентностей у користуванні інформаційно-комунікаційними технологіями.

\section{ЛІТЕРАТУРА:}

1. Положення про дистанційне навчання: наказ Міністерства освіти і науки України від 21.01.2004 р. № 40 . URL: https://zakon.rada.gov.ua/laws/show/z0464-04\#Text (дата звернення 10. 06.2021)

2. Положення про дистанційне навчання: наказ Міністерства освіти і науки України від 25.04.2013 р. № 466. URL: https://zakon.rada.gov.ua/laws/show/z0703-13\#Text (дата звернення 10. 06.2021)

3. Про Національну стратегію розвитку освіти в Україні на період до 2021 року: наказ Президента України від 25.06.2013 p. № 344/2013 URL:http://zakon4.rada.gov.ua/laws/show/344/2013. (дата звернення 10. 06.2021)

4. Семеніхіна О. В., Шамоня В. Г. Віртуальні лабораторії як інструмент навчальної та наукової діяльності. Педагогічні науки: теорія, історія, інноваційні технології. Суми, 2011. № 1 (11). С. 341-346.

5. Трухин А. В. Об использовании виртуальных лабораторий в образовании. Открытое и дистанщионное образование. 2002. № 4 (8). С. 67-69

6. Юрченко А. О., Хворостіна Ю. В. Віртуальна лабораторія як складова сучасного експерименту. Науковий вісник Ужгородського університету. Педагогіка. Соціальна робота. Ужгород, 2016. Вип. 2 (39). С. 281-283.

7. ChemCollective URL: http://chemcollective.org/vlabs (дата звернення 10. 06.2021)

8. PhET URL: https://phet.colorado.edu/uk/simulations/filter?subjects=chemistr (дата звернення 10. 06.2021)

9. Chemist Free- Virtual ChemLab URL: https://play.google.com/store/apps/details?id=air.thix.sciencesense. chemist\&hl=uk\&gl=US (дата звернення 10. 06.2021)

10. VirtuLab URL: http://www.virtulab.net/index.php?option=com_content\&view=category\&layout=blog\&id= 57\&Itemid=108 (дата звернення 10. 06.2021)

\section{REFERENCES:}

1. Polozhennya pro dystantsiyne navchannya (Nakaz Ministerstva osvity i nauky Ukrayiny). [Regulations on distance learning from January 21 2004, № 40. (By order of the Ministry of Education and Science of Ukraine)]. Ofitsiinyi sait Ministerstva osvity i nauky Ukrayiny. [Official website of the Ministry of Education and Science of Ukraine] Retrieved from https://zakon.rada.gov.ua/laws/show/z0464-04\#Text [in Ukrainian]

2. Polozhennya pro dystantsiyne navchannya (Nakaz Ministerstva osvity i nauky Ukrayiny). [Regulations on distance learning from April 25 2013, № 466. (By order of the Ministry of Education and Science of Ukraine)]. Ofitsiinyi sait Ministerstva osvity i nauky Ukrayiny. [Official website of the Ministry of Education and Science of Ukraine] Retrieved from https://zakon.rada.gov.ua/laws/show/z0703-13\#Text [in Ukrainian]

3. Pro Natsional'nu stratehiyu rozvytku osvity v Ukrayini na period do 2021 roku (Nakaz Prezydenta Ukrayiny). [On the National Strategy for the Development of Education in Ukraine until 2021 from June 25 2013, № 344/2013 (By order of the Verkhovna Rada of Ukraine)]. Ofitsiinyi sait Verkhovnoyi Rady Ukrayiny. [Official website of the Verkhovna Rada of Ukraine] Retrieved from URL:http://zakon4.rada.gov.ua/laws/show/344/2013.

4. Semenihina, O. V., Shamonya, V. G. (2011). Virtuani laboratorii yak instrument navchalnoi ta naukovoi dialnosti [Virtual laboratories as a tool for educational and scientific activities]. Pedagogichni nauky: teoria, istoria, innovacijni tehnologii, 1 (11), 341-346. [in Ukrainian]

5. Trukhyn, A. V. (2002). Ob ispol'zovanii virtual'nykh laboratoriy v obrazovanii [On the use of virtual laboratories in education]. Otkrytoye i distantsionnoye obrazovaniye, 4, 67-69. [in Russian]

6. Yurchenko, A. O., Xvorostina, Yu. V. (2016).Virtualna laboratoria yak skladova suchasnogo eksperymentu [Virtual laboratory as a component of modern experiment]. Naukovyj visnyk Uzhgorodskogo universytetu. Pedagogika. Socialna robota, 2 (39), 281-283. [in Ukrainian]

7. ChemCollective (2021) Ofitsiinyi sait virtual'noyi laboratoriyi [Official site virtual laboratory]. Retrieved from http://chemcollective.org/vlabs

8. PhET (2021) Ofitsiinyi sait virtual'noyi laboratoriyi [Official site virtual laboratory]. Retrieved from $\mathrm{https}$ ://phet.colorado.edu/uk/simulations/filter?subjects=chemistr

9. Chemist Free - Virtual ChemLab (2021) Ofitsinyi sait virtual'noyi laboratoriyi [Official site virtual laboratory]. Retrieved from https://play.google.com/store/apps/details?id=air.thix.sciencesense.chemist\&hl=uk\&gl=US

10. VirtuLab (2021) Ofitsiinyi sait virtual'noyi laboratoriyi [Official site virtual laboratory]. Retrieved from http://www.virtulab.net/index.php?option=com_content\&view=category\&layout=blog\&id=57\&Itemid=108 